\title{
Evaluating R\&D Investment Efficiency in China's High-tech Industry
}

\author{
Dr Chunjia Han (corresponding author) \\ Faculty of Business, University of Greenwich, London SE10 9LS, UK \\ chunjia1985@gmail.com
}

Dr Stephen Rhys Thomas

Southampton Business School, University of Southampton, Highfield, Southampton SO1 7 1BJ, UK

Dr Petros leromonachou

Faculty of Business, University of Greenwich, London SE10 9LS, UK 


\title{
Evaluating R\&D Investment Efficiency in China's High-tech Industry
}

\begin{abstract}
Research and development (R\&D) investment activity plays a crucial role in developing high-tech industries. In recent decades, China has made sustained investments in its domestic high-tech industries, with the goal of increasing their productivity. This paper investigates the effect of this investment on relative R\&D efficiency across China's high-tech sectors. Data Envelopment Analysis (DEA) was used to generate quantitative indices for sector comparisons. The analysis of this study indicates that overall R\&D investment efficiency did not increase from 1998 to 2009 , despite R\&D expenditure increasing by $2188 \%$. Over the same period, most sectors suffered from decreasing returns to scale (DRS), presumably also reflecting the inefficient R\&D investment. Most of the sectors showed significant fluctuation on $R \& D$ investment efficiency. This research result indicates that the problem of China's high-tech industry may be from the inefficiency of its technology commercialization processes, and therefore represents a critical parameter for policy makers and managers.
\end{abstract}

\section{Keywords}

Data Envelopment Analysis (DEA); R\&D investment efficiency; China's high-tech industry; Technical efficiency (TE); Pure technical efficiency (PTE); Scale efficiency (SE).

\subsection{Introduction}

The importance of innovation has been widely acknowledged and the growth of high-tech industry has frequently been regarded as the one of most important indices for economic development (Rosegger, 1996; Grossman and Helpman, 1991; Cainelli et al., 2006). This phenomenon is no longer confined to the developed countries; countries from emerging markets have been investing increasingly into the high-tech industry to enhance their capacity for innovation. Although the increasing level of investments would seem likely to promote innovation, it is not clear that this is occurring (see Zabala-Iturriagagoitia et al., 2007). In addition, because of the limitation of resources, investment should be prioritized strategically 
across the various high-tech industries in order to realize optimal levels of innovation and productivity.

Research and development (R\&D) activities provide the basis for many corporate science and technology activities, and play a crucial role in enhancing the competitiveness of companies in achieving sustained and rapid growth (Zhong et al., 2011). In order to improve R\&D efficiency, it is first necessary to measure it, and so quantitative methods have been adapted to analyze the efficiency of $R \& D$ investment as an index of innovation. R\&D investment efficiency is improved when for the same amount of R\&D input more innovation output is generated, or when less $R \& D$ input is needed for generating the same amount of innovation output. Simply, innovation efficiency can be defined as the ratio of outputs over inputs (Hollanders and Celikel-Esser, 2007). Inputs include R\&D expenditure, R\&D personnel and knowledge capital stock, and outputs indicate the technical improvement and economic benefit from the R\&D activities.

Measuring the $R \& D$ investment efficiency from the quantitative perspective is needed to provide practical indices for measuring and managing it, especially in the developing countries. Most of the relevant research is based on advanced markets in which the innovation production systems are more mature (for example, Mansfield, 1998; Timmer, 2003). Although the experiences from these countries are very useful, the particular characteristics of emerging markets decide the necessity and importance of measuring and understanding the R\&D investment efficiency in developing countries.

As one of the main developing countries in the world, China has been making great efforts to develop its R\&D capacity for high-tech industry. Firstly, China's government figures indicate that spending on $R \& D$ has increased dramatically in recent years. R\&D spending has increased by $2794.044 \%$ from 1991 to 2008 . Its $R \& D$ intensity, namely the R\&D spending as a percentage of GDP, climbed from $0.76 \%$ in 1999 to $1.54 \%$ in 2008 . On the global landscape, although China's global share in terms of gross $R \& D$ expenditure remains lower, it is currently the second to third highest investor in R\&D, following the US and Japan. Secondly, from 1995 to 2004 , the number of researchers in China increased by $77 \%$. In 2006, China ranked second worldwide with 926,000 researchers, just behind the U.S. and ahead of Japan. Thirdly, China's patent applications and authorizations showed a doubledigit increase, with an average increase of $16.7 \%$ and 25\%, respectively, from 1986 
to 2007. China's world-ranking in terms of patent application rose from the 22nd place in 1997 to the 7th place in 2007 (China Science and Technology Indicators, 2009; The Royal Society, 2011 ).

With these growing investments aimed at increasing innovation and productivity, China has emerged as the largest high-tech exporting country with $16.9 \%$ of global market share in high-tech products in 2006 (Eurostat's high-tech statistics, 2009). However, China is still far away from the developed countries in independent innovation capability and commercialization capability. For example, In terms of trade forms, $82 \%$ of high-tech exports belong to processing trade in 2009 , i.e., "processed high-tech" exports. Under the category of high-tech products, what China actually exported is low skilled labour rather than technology (Xing, 2011).

A significant literature about the study of China's R\&D capability has developed over the last decade. Zhang et al. (2003) made a contribution about the relationship between ownership and R\&D efficiency based on a sample of 8341 Chinese firms. Guan et al. (2006) studied the relationship between competiveness and technological innovation capability based on the analysis of 182 industrial innovative firms in China. Liu and Buck (2007) investigated the impact of different channels for international technology spill-over on the innovation performance of Chinese high-tech industries. Guan and Chen (2010) developed the measurement of the innovation production process and applied it to a cross-region study of China's high-tech innovation. Zhong et al. (2011) evaluated the relative efficiencies of 30 regional R\&D investments in 2004.

Research on the R\&D productivity in China began with the studies of elements affecting the performance of China's innovation capability. Later on, researchers switched their attention to the measurement of performance on China's R\&D productivity. However, the relative studies in the literature only focused on the cross-region comparison on R\&D investment efficiency. So the research to systematically measure the performance of R\&D efficiency performance in China's high-tech industry based on industry level and the comparison across sectors and sub-sectors is still needed to help understand the innovation capability of China's high-tech industry.

The main econometric methodologies for efficiency and productivity analysis are Data Envelopment Analysis (DEA) and stochastic frontier analysis (SFA). SFA has been adapted to develop the studies about the R\&D productivity. For example, 
Zhang et al. (2003) applied SFA approach to examine the effects of various types of ownership on R\&D efficiency of Chinese firms. Wang (2007) applied SFA approach to evaluate the relative efficiency of aggregate $R \& D$ activities cross 30 countries and observed a positive correlation between R\&D performance and income level. However, there are two disadvantages for SFA technique which make it unsuitable for this research: it only can be used when the production function model is known, and more importantly it cannot accommodate many inputs and many outputs (Avkiran and Rowlands, 2008; Iglesias et al., 2010; Reinhard et al., 2000). DEA, in contrast, has several advantages in terms of evaluating the relative efficiency of R\&D activities: firstly, DEA is especially valuable where therelative importance of the various inputs employed andoutputs produced by a DMU (decision making units)cannot be defined; secondly, DEA allows for efficiency evaluation without necessitating the specification of a functional representation of the R\&D/knowledge production technology; thirdly, R\&D activities typically involves multiple inputs and multiple outputs (Wang and Huang, 2007).

Therefore, Data Envelopment Analysis (DEA) was employed to evaluate the R\&D investment efficiency in this research. DEA has been widely used to evaluate the efficiency and productivity of many different kinds of entities ranging from manufacturing industry to service industry, and activities including cost efficiency measurement and operating efficiency measurement, as well as in contexts from emerging market to advanced market (Cooper et al., 2004).

Specifically, in this study the following three questions were addressed: Firstly, What change did the entire $R \& D$ investment efficiency of China's high-tech industry undergo during 1998 to 2009? Secondly, what was the relative performance of China's five major high-tech sectors in terms of R\&D investment efficiency? Finally, what factors triggered this performance and what are their implications for the future performance landscape?

The remainder of this paper is organized as follows. Section 2.2 explains the research design including DEA model, research procedure, variable measurement and sample selection. Section 2.3 provides the empirical results of DEA and individual output/input ratio analysis applied to the whole industry, the five hightech sectors and sixteen sub-sectors.Finally, section 2.4 discusses the results and makes the conclusion. 


\subsection{Research Design}

\subsubsection{The DEA Model}

DEA is a mathematical programming methodology, which is applied to assess production efficiency by using multiple inputsand outputs (see,e.g., Kozmetsky and Yue, 1998; Yeh, 1996). The ground breaking work done by Rousseau and Rousseau (1997, 1998) proved the potential of DEA-analysis to assess R\&D activities. Subsequent studies (see, e.g., Guan and Chen, 2010; Chen et al., 2006; ZabalaIturriagagoitia et al., 2007; Zhong et al., 2011) have provided supporting evidence for its use in evaluating the innovation efficiency, especially for the high-tech industries. Two DEA models are used in this thesis: CCR model (Charnes et al., 1978) and the BCC model (Banker et al., 1984). The CCR model is designed under the assumption that production exhibits constant returns to scale. The BCC model, on the other hand, assumes that there are variable returns to scale (Wang and Huang, 2007). Therefore, in the CCR model there is a linear relation between inputs and outputs; while in the BCC model, outputs can increase by a variable percentage, depending on its position on the efficiency frontier (Hollanders and Celikel-Esser, 2007). The following sectiondescribes the two models in more detail.

Assume that there are $n$ DMUs (decision making units) $\left(\operatorname{DMU}_{j}, j=1,2, \ldots, n\right)$. Each $\mathrm{DMU}_{j}$ contains $m$ inputs $x_{i j}(i=1,2, \ldots m)$ and $s$ outputs $y_{r j}(r=1,2, \ldots s)$. So the $\mathrm{m}^{* \mathrm{n}}$ input matrix, $X$, and $s^{*} n$ output matrix, $Y$, represent the data of all $n$ DMUs. The efficiency rate of a unit $\mathrm{DMU}_{j}$ can be generally expressed as:

$$
\frac{\text { weighted sum of outputs }}{\text { weighted sum of inputs }}=\frac{\sum_{r=1}^{s} u_{r} y_{r j}}{\sum_{i=1}^{m} v_{i} x_{i j}}
$$

where $u_{r}(r=1,2, \ldots s)$ and $v_{i}(i=1,2, \ldots m)$ are separately output weights and input weights. The essence of DEA models in measuring the efficiency of productive unit $\mathrm{DMU}_{j}$ lies in maximising its efficiency rate but subject to two conditions as follows.

- The efficiency rate of any other units must not be greater than one.

- The model must include all characteristics considered, that is the weights of all inputs and outputs must not be smaller than zero.

$\operatorname{LetDMU}_{o}$ be the one to be evaluated. Define $u$ as an $s^{*} 1$ vector of output weights (i.e., $\left.\mathrm{u}=\left(\mathrm{u}_{1}, \cdots, \mathrm{u}_{\mathrm{s}}\right)\right)$, and $v$ as an $m^{*} 1$ vector of input weights (i.e., $v=\left(\mathrm{v}_{1}, \cdots, \mathrm{v}_{\mathrm{m}}\right)$ ). The 
input-output vector of $\mathrm{DMU}_{o}$ is $\left(x_{o}, y_{o}\right)$. To satisfy the two conditions, the general DEA model is defined as a linear divisive programming model:

$$
\max _{u, v} \quad\left(u y_{o} / v x_{o}\right)
$$

subject to $u Y / v X \leq 1$

$$
u, v \geq 0
$$

To make sure the above model has an infinite number of solutions $(u, v)$, we impose $v x_{o}=1$. Then we have

$$
\max _{u, v} \quad\left(u^{\prime} y_{o}\right)
$$

subject to $\quad v^{\prime} x_{o}=1$

$$
\begin{gathered}
u^{\prime} Y-v^{\prime} X \leq 0 \\
u^{\prime}, v^{\prime} \geq 0
\end{gathered}
$$

where $u^{\prime}, v^{\prime}$ are the notions changed from $u, v$ reflecting the transformation.

By using the duality in linear programming, the model (2) can be converted into a linear programming model which is called CCR model or BCC model by adding a constraint. In particular, let $\theta$ be the efficiency score and $\lambda$ bea $n^{*} 1$ vector of constants. The CCR model is defined as:

$\min _{\theta, \lambda} \theta$

s.t. $\theta x_{o} \geq X \lambda$

$$
\begin{gathered}
Y \lambda \geq y_{o} \\
\lambda \geq 0
\end{gathered}
$$

Here $\theta$ is a scalar and its value is not greater than one. With a value equals to one, it indicates such DMU is technically efficient.

The BCC model adds the convexity constraint. It is shown as follows:

$\min _{\theta, \lambda} \theta$

s.t. $\theta x_{o} \geq X \lambda$

$$
Y \lambda \geq y_{o}
$$


$\Sigma \lambda=1$

$\lambda \geq 0(4)$

Again, $\mathrm{DMU}_{o}$ is technically efficient if $\theta$ is equal to one.

\subsubsection{Research Procedure}

The study looks at three levels. Firstly, at the industry level it examines the R\&D investment efficiency of the whole China's high-tech industry between 1998 and 2009. Secondly, at the sector level, the performance of five China's high-tech sectors on the R\&D investment efficiency from 1998 to 2008 is evaluated. The evaluation is based on the DEA test and individual output/input ratio analysis. Finally, in order to explore more deeply any efficiency changes associated with the R\&D investment, the performance of 16 sub-sectors over time is examined by comparison of the years 2001 and 2008 .

Both the CCR and BCC variants of the DEA model are employed in this research. This permits the calculation of the technical efficiency (TE) score, pure technical efficiency (PTE) score and scale efficiency (SE) score. The TE score is calculated as the ratio of the actual productivity to the maximum attainable productivity (Sharma and Thomas, 2008). It is calculated in the CCR DEA model under the assumption of constant returns to scale: in this case, the maximum attainable productivity is presented as the distance from the constant returns to scale frontier. The PTE score is calculated in the BCC DEA modelas the ratio of the actual productivity to the maximum attainable productivity: in this case,the maximum attainable productivity represents the distance from the variable returns to scale frontier, which means, in contrast to the TE score, the PTE score excludes scale effects (Gulati, 2011). The SE score can be derived from the BCC model if the technology exhibits variable returns to scale. If there is a difference between the TE score and PTE score for a particular sector DMU, then this unit is characterized by scale inefficiency (Wang and Huang, 2007). The SE score is then defined as the ratio of constant returns to scale Technical Efficiency to the Variable Returns to Scale Technical Efficiency (Sharma and Thomas, 2008). Once the BCC is established, the analysis can be used to determine whether a particular DMU is experiencing increasing, constant, or decreasing returns to scale (Chen et al., 2006). Thus the DEA analysis process generated three key indices: the SE scores, PTE scores and TE scores. These scores 
can then be used to evaluate the R\&D investment efficiency by industry, sector, or company over time.

\subsubsection{Variable Measurement and Sample Selection}

\subsubsection{Input Parameters}

Industrial R\&D investment is often a complex process, with multiple inputs and outputs. One of the advantages of adopting the DEA analysis is that multiple inputs and outputs can be measured more than can be accommodated using conventional econometric techniques (Cooper et al., 2004). This multiple DEA analysis study was begun by selecting the appropriate inputs and outputs based on the previous literature. The inputs to innovation production activities are physical resources and mainly manpower, which are usually measured in annual total R\&D expenditures and R\&D personnel (Wang and Huang, 2007).

The $R \& D$ expenditure refers to the total internal expense, covering all projects involving fundamental research, applied research or experimental development, as well as the 'overhead' expenses related to the management and services for these projects (Zhong et al., 2011). In this case, the internal expenditure of R\&D funding is employed to represent the R\&D expenditure index. Since the study focuses on industrial R\&D investment efficiency, only internal expense is included (exclusive of external).This R\&D expense input index has been widely used, and found to be suitable in previous studies (Guan and Chen, 2010; Zhong et al., 2011; Chen et al., 2006).

The R\&D personnel input figure includes all staff are engaged in either fundamental research, application research or experimental development (Zhong et al., 2011). The number of research staff on R\&D activities can be taken as the R\&D personnel input index. However, based on the previous studies, the full-time equivalence (FTE) cost of scientists and technologists on $R \& D$ activities was adopted as the $R \& D$ personnel input index, since the R\&D personnel input index is considered to be more accurate than the research staff number.

However, for the macro-level analysis such as the industry study on country level, the effect of knowledge capital stock should also be considered, especially for the developing country due to their knowledge capital stock is changing dramatically and has strong potential impact to the country's future innovation performance. 
The support evidence comes from the basic hypothesis behind Romer's knowledge production function (Romer, 1990), which is the idea generation does not "fall from heaven", but derives fromprior knowledge stock available and human capital (Guan and Chen, 2010).Therefore, knowledge capital stock is employed as the third input in this research. The accumulated patents stock is used as a proxy measure of knowledge capital stock, which is consistent with prior studies (see Furman et al., 2002; Hu and Mathews, 2008).

\subsubsection{Output Parameters}

The process of innovation production is complex. If we consider all the details in this process, it will be impossible to measure its performance. Therefore, the former studies tried to simplify the whole process to make it possible to be measured, without affecting the final result (see Guan and Chen, 2010). The acceptable process could be a system that first obtains technology, then transforms the technology into specific product development achievements, and finally to output by extending R\&D activities to productive development and commercial activities (Zhong et al., 2011). So the main outputs of industrial R\&D activities are not only technical improvements, but also include economic benefits.

The initial, direct outcome of R\&D investment is technical improvement. The patents may be the most appropriate proxy of this technical improvement (see Guan and Chen, 2010; Wang and Huang, 2007). Although not all inventions are patentable or patented and the inventions which are patented have different quality (Griliches, 1990), former studies including empirical evidence indicate that patents provide a fairly reliable measure of innovation production activities (see Acs et al., 2002; Pakes and Griliches, 1984). Therefore, this study employed the number of patent applications to measure the technical improvement. Here the number of patent applications refers to the quantity of accepted patent applications given to the sector/sub-sector by the patent office in the given year.

Economic benefit is the key purpose of company's R\&D investment behaviour. The success or failure of innovation activities on economic benefit could be observed from the performance of sales and revenues, particularly on new products. As Freeman and Soete (1997) discussed, an innovation in theeconomic sense is accomplished only with the first commercialtransaction. Therefore, two indices value-added from new products and the sale revenue for new products - which record the economic performance of new products, are adapted in this research. 
Here value-added from new products refers to the value-added achieved from the development of new products in the given year. The sale revenue for new products refers to the sale revenue achieved from sales of new products in the given year.

\subsubsection{Time Lag Effects}

Previous studies indicated that time lags between the inputs and the outputs could be important factors. However, there is no generally accepted time lag for R\&D inputs and outputs. Goto and Suzuki (1989) studied the average time before the sale of a product resulting from R\&D technology based on survey data for Japanese firms and found that the time lag varied among major industries. Adams and Griliches (2000) studied the relationship between research output and R\&D in eight fields of university research, and considered the time lag to be 5 years. Guellec and van Pottelsberghe de la Potterie (2004) considered the lag effects of business and public R\&D capital stocks on multi-factor productivity growth of 16 countries to be 1 and 2 years, respectively. Wang and Hua (2007) conducted a preliminary test, which showed that a 3-year lag is most appropriate in the study of relative efficiency of R\&D activities across countries when using aggregate data.Guan and Chen (2010) conducted a preliminary test of time lags, using a series of correlation and regression analyses, and concluded that the most appropriate time lags for the efficiency study of China's R\&D activity would be 2-year lag for the R\&D process and 1-year lag for the commercialization process. Following these studies, the preliminary test was given in this study aimed to find the suitable time lag between inputs and outputs, which shows that 2-year lag for the applied patent number and 1-year lag for the value-added from new products and the sale revenue for new products are appropriate (For example, if the dataset of the inputs is from the statistical data in 2003, the output data of the applied patent number should come from the statistical data in 2005 with 2-year lag, and the outputs data of the valueadded from new products and the sale revenue for new products should come from the statistical data in 2006 with 1 -year lag).

There are normally two ways to test the robustness of DEA analysis results: firstly, by choosing two consecutive cross-sectional datasets to provide an approach for a robustness test by longitudinal comparisons (see Guan and Chen, 2010; ZabalaIturriagagoitia et al., 2007); secondly, by varying the length of time lags to provide a robustness test (e.g., Hollanders and Celikel-Esser, 2007). Due to this study utilising panel data, the cross-sectional dataset already included into the data 
analysis. For the other robustness test, two different time lags were selected and adapted, in order to see whether current introduction of time lag has an effect of the final results. These two time lags are 2 years' lag which shows that 1 -year lag for the applied patent number and 1 -year lag for the commercial revenue, and 4 years' lag which shows 3-year lag for the applied patent number and 1-year lag for the commercial revenue. The analysis results show that, although the exact score per sector per year has changed, the general performance of each sector looks similar which indicates that current introduction of time lag has limited effect on the general analysis results. And because this 3 years' time lag was selected based on preliminary test, it is more suitable to be adapted in this study. The analysis of results from the other two time lags (2 years' lag and 4 years' lag) can been seen in the appendix (Table A.1-6).

Another potential issue is the time lag difference among sectors. The product development lead time in different sectors is different (see Arundel et al., 1995). To avoid this difference affecting the research result, a test of time lag was needed. Based on the above tests which adapted two other time lag choices (2-year time lag and 4-year time lag), we can see that for most of sectors the performance and ranking are stable in the test results. This indicates that the time lag adopted in this study is broadly suitable. However, from the experience in mature market, the Medicine sector - as defined in this database - normally has much longer product lead time since its characteristics and regulation (see Munos, 2009). Therefore, one test was developed through adoption of longer time lag for the Medicine sector to observe whether the time lag difference has an effect for the result. 8-year time lag was employed in this test,in line with previous studies (Hashimoto and Haneda, 2008; Odagiri and Murakami; 1992).

The test result is documented in the Appendix (Table A.7-9). Due to the limitations of the time lag effect, only a short period performance of the Medicine sector (2003-2008) could be observed. Comparing the research results from four tests of time lag, the general performance of the Medicine sector with 8-year time lag is consistent with the ones from other tests which showed the trend of improvement on R\&D efficiency. However, with an 8-year time lag, the R\&D efficiency of the Medicine sector ranked at second among all sectors, even higher than the Electronics sector (EEACE) and the Instrument sector (MEAMI), which was not observed at other time lags. With the comparison of expenditure for new product development, labour productivity and gross industrial output value, the Medicine 
sector shows lower performance than Electronics sector (see Ministry of Science and Technology of the People's Republic of China, 2011). The differing test results indicate that the 8-year time lag is not suitable for China's medicine sector. The 8year time lag is broadly accepted in pharmaceutical industry studies of mature markets such as Japan, America and Europe (for example Hashimoto and Haneda, 2008). However, comparing with mature markets, the China's medicine sector has a different situation. China was still staying at the imitative innovation stage in their pharmaceutical industry during the test period of 1993-2008 (Ding et al., 2011). One of the potential explanations is that the time required for clinical trials and drug approvals in China is shorter than time in mature markets (Wang and Kang, 2005). Therefore, based on the analysis, the time lag of the Medicine sector adapted in this research is consistent with the one for other sectors.

\subsubsection{Data Sources}

As the subject of this first study is China's high-tech industry, both data of inputs and outputsfrom 1995-2009 were taken from China's Statistics Yearbook on Hightech industries, as compiled by the Chinese State Statistical Bureau. China's hightech industry is divided into 5 sectors and 21 sub-sectors according to the categorization in the yearbook. The dataset includes the sectors of Manufacture of Medicines (with 3 sub-sectors), Manufacture of Aircraft and Spacecraft (with 2 subsectors), Manufacture of Electronic Equipment and Communication Equipment (11 sub-sectors), Manufacture of Computers and Office Equipment (with 3 sub-sectors), and Manufacture of Medical Equipment and Measuring Instrument (with 2 subsectors). Their categorization of China's high-tech industry in that yearbook is shown in Table 2.1. Based on that categorization, the R\&D investment efficiency could be analysed at three distinct levels: the whole high-tech industry, the five big high-tech sectors and the 16 high-tech sub-sectors. The primary results are summarized below. This is the most up-to-date and detailed data on China's hightech industry currently available.

All financial inputs and outputs were expressed in Chinese currency, as 10,000s RMB $\$$ Since the duration of the sample period was more than ten years, the expenditure indicators were adjusted by comparable price index in 1995, to remove the inflation impact over period.The basic statistics for the main variables used to study the R\&D performance of China's high-tech industry from three levels 
(whole industry, sectors and sub-sectors) are reported respectively in Table 2.2, Table 2.3 and Table 2.4.

Table 0.1: Categories of China's high-tech industry

\begin{tabular}{|c|c|c|c|c|}
\hline NO. & Sectors & Abbr. & NO. & Sub-sectors* \\
\hline \multirow[t]{3}{*}{1} & \multirow[t]{3}{*}{ Manufacture of Medicines } & \multirow[t]{3}{*}{ Medicines } & 1 & Manufacture of Chemical Medicine \\
\hline & & & 2 & $\begin{array}{l}\text { Manufacture of Finished Traditional Chinese } \\
\text { Herbal Medicine }\end{array}$ \\
\hline & & & 3 & $\begin{array}{l}\text { Manufacture of Biological and Biochemical } \\
\text { Chemical Products }\end{array}$ \\
\hline \multirow[t]{2}{*}{2} & \multirow{2}{*}{$\begin{array}{l}\text { Manufacture of Aircrafts and } \\
\text { Spacecraft }\end{array}$} & \multirow[t]{2}{*}{ AAS } & 4 & Manufacture and Repairing of Airplanes \\
\hline & & & 5 & Manufacture of Spacecraft \\
\hline \multirow[t]{11}{*}{3} & \multirow{11}{*}{$\begin{array}{l}\text { Manufacture of Electronic } \\
\text { Equipment and } \\
\text { Communication Equipment }\end{array}$} & \multirow[t]{11}{*}{ EEACE } & 6 & $\begin{array}{l}\text { Manufacture of Communication Transmitting } \\
\text { Equipment }\end{array}$ \\
\hline & & & 7 & $\begin{array}{l}\text { Manufacture of Communication Exchanging } \\
\text { Equipment }\end{array}$ \\
\hline & & & 8 & $\begin{array}{l}\text { Manufacture of Communication Terminal } \\
\text { Equipment }\end{array}$ \\
\hline & & & 9 & Manufacture of Radar and its Fittings \\
\hline & & & 10 & Manufacture of Broadcasting and TV Equipment \\
\hline & & & 11 & Manufacture of Electronic Vacuum Appliances \\
\hline & & & 12 & Manufacture of Semiconductor Appliances \\
\hline & & & 13 & Manufacture of Integrate Circuit \\
\hline & & & 14 & Manufacture of Electronic Components \\
\hline & & & 15 & $\begin{array}{l}\text { Manufacture of Domestic TV Sets and Radio } \\
\text { Receivers }\end{array}$ \\
\hline & & & 16 & Manufacture of Other Electronic Equipment \\
\hline \multirow[t]{3}{*}{4} & \multirow{3}{*}{$\begin{array}{l}\text { Manufacture of Computers } \\
\text { and Office Equipment }\end{array}$} & \multirow[t]{3}{*}{ CAOE } & 17 & Manufacture of Entire Computer \\
\hline & & & 18 & Manufacture of Computer Peripheral Equipment \\
\hline & & & 19 & Manufacture of Office Equipment \\
\hline \multirow[t]{2}{*}{5} & \multirow{2}{*}{$\begin{array}{l}\text { Manufacture of Medical } \\
\text { Equipment and Measuring } \\
\text { Instrument }\end{array}$} & \multirow[t]{2}{*}{ MEAMI } & 20 & $\begin{array}{l}\text { Manufacture of Medical Equipment and } \\
\text { Appliances }\end{array}$ \\
\hline & & & 21 & Manufacture of Measuring Instrument \\
\hline \multicolumn{5}{|c|}{$\begin{array}{l}\text { *There are } 21 \text { sub-sectors in categories of China's high-tech industry. Due to the lack of data in some sub- } \\
\text { sectors, only } 16 \text { sub-sectors met the completeness criteria for this research. (Sub-sectors NO. 5, 7, 9, 10, } 19 \\
\text { were excluded). }\end{array}$} \\
\hline
\end{tabular}


Table 0.2: Descriptive statistics for main variables in the whole industry study

\begin{tabular}{|c|c|c|c|c|}
\hline Variables & Mean & $\begin{array}{l}\text { Standard } \\
\text { deviation }\end{array}$ & Maximum & Minimum \\
\hline$R \& D$ expenditure & 1616497 & 1296985.664 & 4084257.48 & 178474.1 \\
\hline $\begin{array}{l}\text { Full-time equivalent of R\&D } \\
\text { personnel }\end{array}$ & 111700.7 & 38337.46342 & 188986.54 & 57838 \\
\hline Accumulated patents stock & 2518 & 2627.829523 & 8141 & 312 \\
\hline Patent applications & 12417.25 & 13564.50523 & 39656 & 713 \\
\hline $\begin{array}{l}\text { Value-added from new } \\
\text { products }\end{array}$ & 56663054 & 33088083.42 & 107298051 & 14243655 \\
\hline Sale revenue for new products & 55305287 & 33364143.32 & 108102978.8 & 12272350 \\
\hline Sample size of DMU & 12 & & & \\
\hline \multicolumn{5}{|c|}{$\begin{array}{l}\text { Data sources: Data comes from China Statistics Yearbook on High-tech industries, as compiled } \\
\text { by the Chinese State Statistical Bureau. China's high-tech industry is divided into } 5 \text { sectors and } \\
21 \text { sub-sectors according to the categorization in the yearbook. This is the descriptive } \\
\text { statistics of data in the first level study about the whole China's high-tech industry. Here the } \\
\text { unit of R\&D expenditure, value-added from new products and sale revenue for new products } \\
\text { is } 10,000 \text { RMB\$; the unit of patent applications and accumulated patent stock is item. }\end{array}$} \\
\hline
\end{tabular}

Table 0.3: Descriptive statistics for main variables in 16 sub-sectors study

\begin{tabular}{|c|c|c|c|c|}
\hline Variables & Mean & $\begin{array}{l}\text { Standard } \\
\text { deviation }\end{array}$ & Maximum & Minimum \\
\hline R\&D expenditure (2001) & 23305 & 24029.9 & 88187.82 & 2944.948 \\
\hline R\&D personnel (2001) & 3343.875 & 3520.659 & 14425 & 844 \\
\hline Accumulated patents stock (2001) & 44.625 & 56.74725 & 175 & 4 \\
\hline Patent applications (2001) & 106.4375 & 98.98079 & 331 & 6 \\
\hline Value-added from new products (2001) & 1696668 & 2145986 & 7447041 & 132983.9 \\
\hline Sale revenue for new products (2001) & 1648856 & 2039920 & 6811947 & 106166.1 \\
\hline$R \& D$ expenditure (2008) & 137491.6 & 119556.2 & 461649.2 & 18802.78 \\
\hline R\&D personnel (2008) & 7373.378 & 6841.567 & 27720.36 & 1262.46 \\
\hline Accumulated patents stock (2008) & 229.5 & 181.1706 & 501 & 11 \\
\hline Patent applications (2008) & 1074.938 & 920.0535 & 3614 & 47 \\
\hline Value-added from new products (2008) & 4732791 & 5812012 & 20841837 & 629713.7 \\
\hline Sale revenue for new products (2008) & 4650793 & 5812697 & 20279665 & 584431.5 \\
\hline Sample size of DMU & 55 & & & \\
\hline \multicolumn{5}{|c|}{$\begin{array}{l}\text { Data sources: Data comes from China Statistics Yearbook on High-tech industries, as compiled } \\
\text { by the Chinese State Statistical Bureau. China's high-tech industry is divided into } 5 \text { sectors and } \\
21 \text { sub-sectors according to the categorization in the yearbook. This is the descriptive } \\
\text { statistics of data in the third level study about the comparison research of } 16 \text { sub-sectors } \\
\text { from China's high-tech industry in } 2001 \text { and } 2008 \text {. Here the unit of R\&D expenditure, value- } \\
\text { added from new products and sale revenue for new products is 10,000 RMBS; the unit of } \\
\text { patent applications and accumulated patent stock is item. }\end{array}$} \\
\hline
\end{tabular}

Table 0.4: Descriptive statistics for main variables in five sectors study

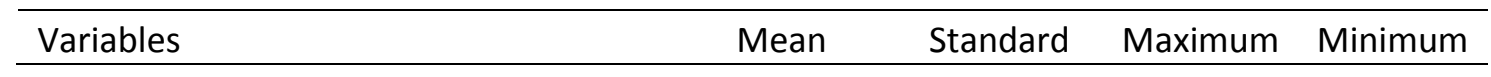




\begin{tabular}{|c|c|c|c|c|}
\hline & & deviation & & \\
\hline R\&D expenditure (Medicines) & 165645.2 & 110542.9 & 368216 & 42785 \\
\hline R\&D personnel (Medicines) & 13841.83 & 3370.09 & 19584.38 & 9528 \\
\hline Accumulated patents stock (Medicines) & 417 & 326.526 & 1134 & 113 \\
\hline Patent applications (Medicines) & 1294.909 & 1026.891 & 3056 & 257 \\
\hline $\begin{array}{l}\text { Value-added from new products } \\
\text { (Medicines) }\end{array}$ & 3866045 & 2261652 & 8279468 & 1273707 \\
\hline Sale revenue for new products & & & & \\
\hline (Medicines) & 3536810 & 2130015 & 7705194 & 1056384 \\
\hline R\&D expenditure (AAS) & 152167.6 & 76563.53 & 256195.5 & 65067 \\
\hline R\&D personnel (AAS) & 30680.5 & 6758.321 & 40748 & 18145 \\
\hline Accumulated patents stock (AAS) & 108.7273 & 51.74957 & 192 & 38 \\
\hline Patent applications (AAS) & 247.2727 & 229.9 & 810 & 79 \\
\hline Value-added from new products (AAS) & 2095044 & 1227502 & 3822463 & 428448.7 \\
\hline Sale revenue for new products (AAS) & 1952164 & 1193183 & 3840623 & 352557.1 \\
\hline R\&D expenditure (EEACE) & 859331.6 & 725592.8 & 2163308 & 51289 \\
\hline R\&D personnel (EEACE) & 44156.15 & 22345.48 & 95091.24 & 15398 \\
\hline Accumulated patents stock (EEACE) & 1104 & 1326.545 & 4268 & 84 \\
\hline Patent applications (EEACE) & 6499.091 & 7946.413 & 24680 & 243 \\
\hline Value-added from new products (EEACE) & 30395572 & 15549722 & 54364062 & 9887901 \\
\hline Sale revenue for new products (EEACE) & 29618161 & 15819338 & 54883987 & 8173422 \\
\hline R\&D expenditure (CAOE) & 159545.3 & 142948.5 & 400446.3 & 5473 \\
\hline R\&D personnel (CAOE) & 7647.945 & 4863.667 & 17483.75 & 1355 \\
\hline Accumulated patents stock (CAOE) & 171.1818 & 227.9126 & 711 & 6 \\
\hline Patent applications (CAOE) & 1177.727 & 1178.783 & 3266 & 34 \\
\hline Value-added from new products (CAOE) & 14116942 & 10742944 & 35056725 & 2228038 \\
\hline Sale revenue for new products (CAOE) & 13903414 & 10645668 & 34329416 & 2293097 \\
\hline R\&D expenditure (MEAMI) & 55466.04 & 42979.41 & 152869.9 & 13860 \\
\hline R\&D personnel (MEAMI) & 8348.066 & 1094.947 & 11132.08 & 6788 \\
\hline Accumulated patents stock (MEAMI) & 205.9091 & 177.1798 & 591 & 41 \\
\hline Patent applications (MEAMI) & 722 & 756.983 & 2634 & 100 \\
\hline Value-added from new products (MEAMI) & 1586269 & 1242651 & 4186301 & 425559.7 \\
\hline Sale revenue for new products (MEAMI) & 1494948 & 1158180 & 3822655 & 396889.9 \\
\hline Sample size of DMU & 32 & & & \\
\hline $\begin{array}{l}\text { Data sources: Data comes from China } \\
\text { compiled by the Chinese State Statistical B } \\
\text { sectors and } 21 \text { sub-sectors according to } \\
\text { descriptive statistics of data in the second } \\
\text { tech industry. Here the unit of R\&D expen } \\
\text { revenue for new products is } 10,000 \text { RMB\$; } \\
\text { patent stock is item. }\end{array}$ & cule, value & pout the fiv & h-tech ir & $\begin{array}{l}\text { lustries, as } \\
\text { ided into } 5 \\
\text { This is the } \\
\text { ina's high- } \\
\text { ts and sale } \\
\text { cumulated }\end{array}$ \\
\hline
\end{tabular}




\subsection{Empirical Results}

\subsubsection{Overall Efficiency of China's High-tech Industry}

The R\&D investment efficiency across the high-tech industry sectors was examined for the period 1998 to 2009, and the final results, including TE score, PTE score and SE score are summarized in Table 2.5. Examination at the whole high-tech industry level indicates that the R\&D investment efficiency in China's high-tech industry was mostly unchanged over the period 1998 to 2009 (see Table 2.5). This was despite rising $R \& D$ expenditure over the period.

Table 0.5: Efficiency scores and returns to scale of the whole high-tech industry in years 1998-2009

\begin{tabular}{lllll}
\hline Year & $\begin{array}{l}\text { Technical } \\
\text { Efficiency }\end{array}$ & $\begin{array}{l}\text { Pure } \\
\text { Technical } \\
\text { Efficiency }\end{array}$ & $\begin{array}{l}\text { Scale } \\
\text { Efficiency }\end{array}$ & $\begin{array}{l}\text { Returns } \\
\text { To Scale }\end{array}$ \\
\hline 1998 & 1 & 1 & 1 & - \\
1999 & 0.904 & 1 & 0.904 & irs \\
2000 & 1 & 1 & 1 & - \\
2001 & 1 & 1 & 1 & - \\
2002 & 1 & 1 & 1 & - \\
2003 & 1 & 1 & 1 & - \\
2004 & 1 & 1 & 1 & - \\
2005 & 1 & 1 & 1 & - \\
2006 & 0.948 & 0.975 & 0.973 & drs \\
2007 & 1 & 1 & 1 & - \\
2008 & 1 & 1 & 1 & - \\
2009 & 1 & 1 & 1 & - \\
Average & 0.988 & 0.998 & 0.99 & \\
irs and drs stand for increasing and decreasing returns \\
to scale, respectively.
\end{tabular}

The only two obvious changes were the downturns in years 1999 and 2006. Both of these appear to result from reductions in Scale Efficiency (SE); however, the first downturn was associated with increasing returns to scale (IRS) and the second with decreasing returns to scale (DRS). Except for these two years, all the other R\&D investment efficiencies from 1998 to 2009 were unchanged. The potential conclusion is that, even with more than ten yearsdevelopment, the R\&D investment efficiency in China's high-tech industry has not exhibited any dramatic improvement. 


\subsubsection{Patents Performance}

This result suggests a disappointing prospect for the development of China's hightech industry investment. To investigate further the factors which may underlie the unchanged efficiency, the growth ratios of the inputs and outputs were analysed further (Figure 2.1). This analysis showed that although increasing R\&D expenditure appeared to be correlated with a dramatic increase in the number of patent applications, there only appeared to be a limited economic benefit in terms of new high-tech product revenues. This finding in turn may suggest that although increasing R\&D investment (inputs) does appear to have improved the efficiency of technology production in terms of patents, this improvement did not result in a complementary increase in new product revenue, suggesting that the commercialization process for technology was still inefficient. Thiswould explain, at least in part, the flat R\&D performance of the whole high-tech industry over the period of observation. However, this does not rule out a positive longer-term effect; this point is revisited in the discussion.

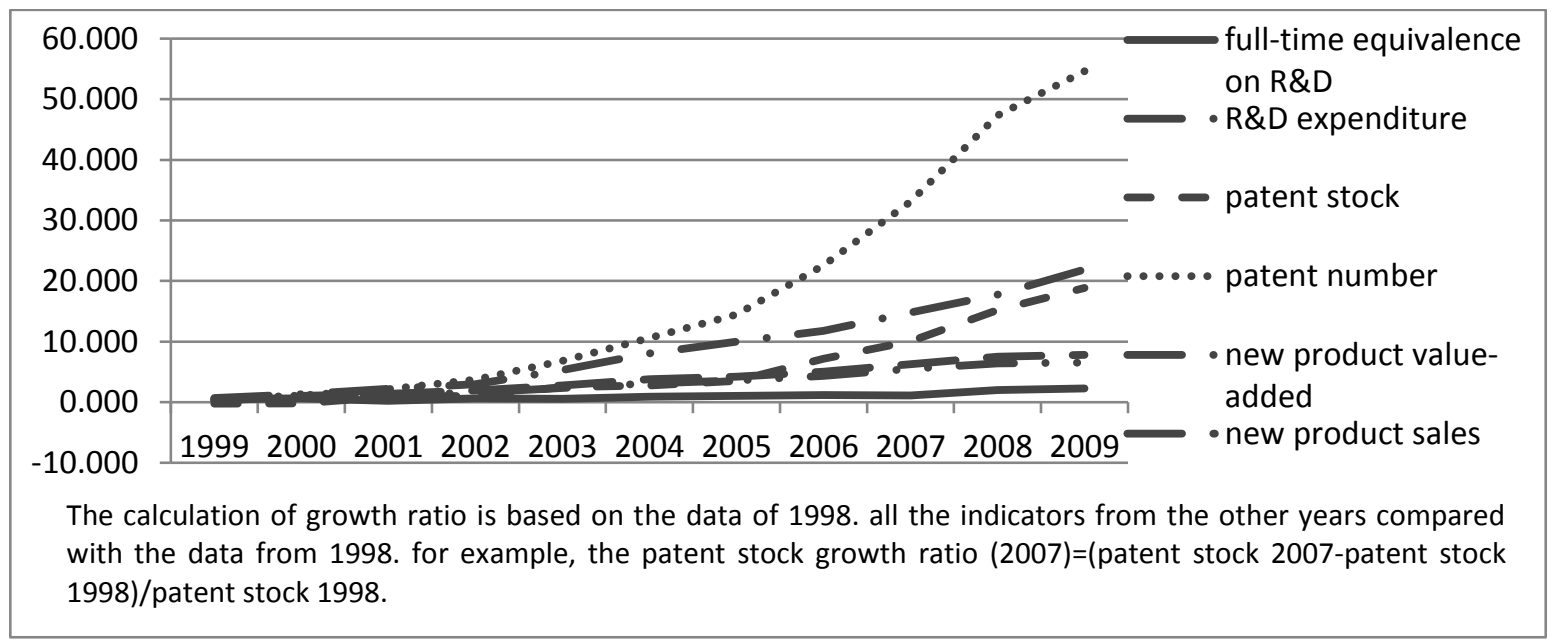

Figure 0.1 : The growth ratio of R\&D investment inputs and outputs

\subsubsection{Further Analysis}

\subsubsection{Technical Efficiency}

The TE scores reflect the overall R\&D investment efficiency. Most of the sectors showed significant fluctuation over the period (see Table 2.6 and Figure 2.2). The R\&D investment efficiency of the Computer sector (CAOE) was consistently the highest until 2006. The Electronics sector (EEACE) and the Instrument sector (MEAMI) 
followed the Computer sector until 2006, but then overtook it in 2007 and 2008 . Aerospace (AAS) was the lowest-performing sector of the five high-tech sectors.

Table 0.6: Technical efficiency scores of five sectors in years 1998-2008

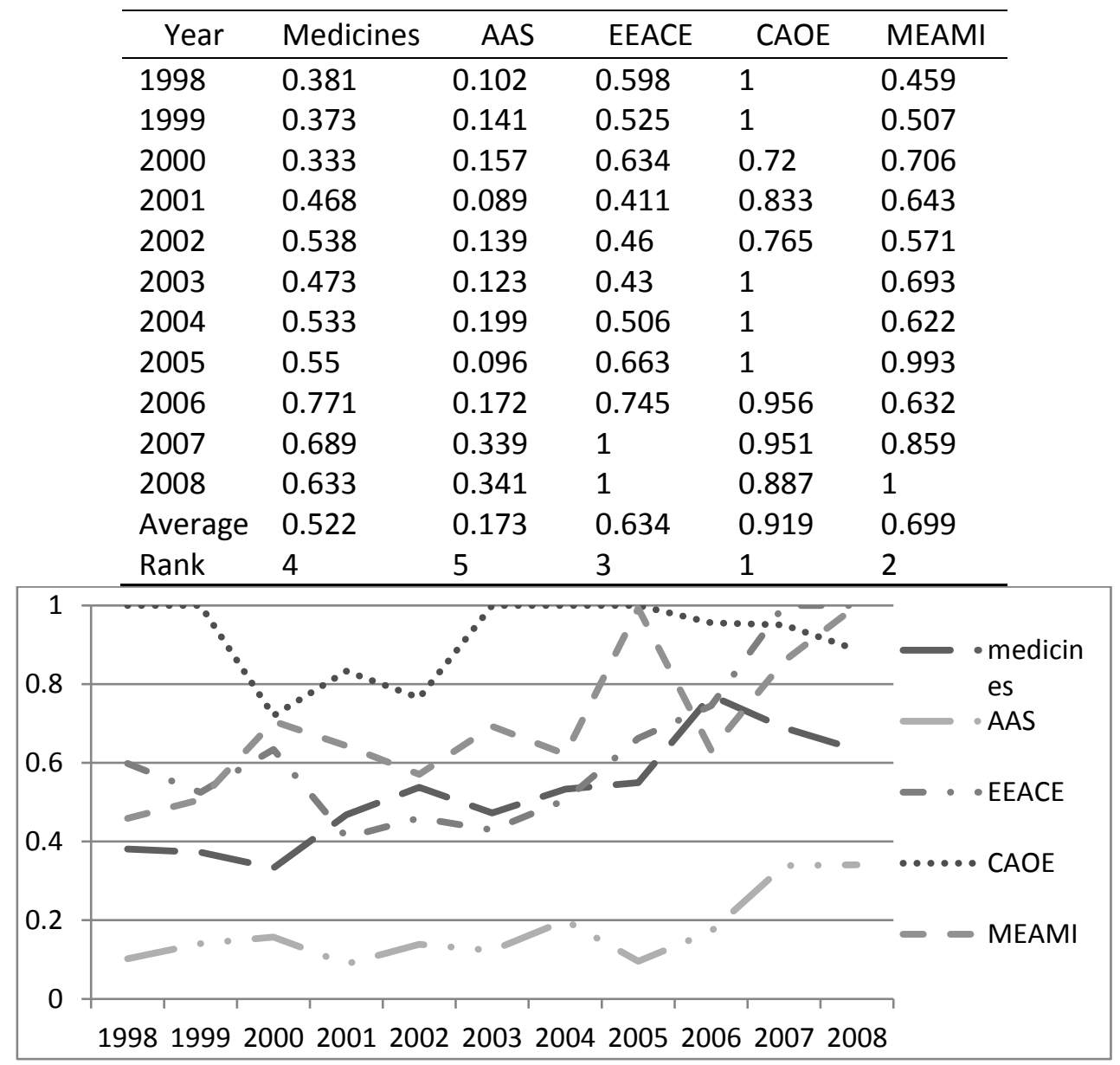

Figure 0.2: The annual variation of the R\&D investment TE in five high-tech sectors from 1998 to 2008

\subsubsection{Pure Technical Efficiency (PTE)}

The PTE scores, which reflect the pure R\&D investment efficiency excluding scale effects, showed a similar pattern of fluctuation and change to the TE analysis. The Computer sector achieved the highest and most consistent PTE scores from 1998 through to 2008 (see Table 2.7 and Figure 2.3). The PTE scores of the Electronics sector were the second highest but fluctuated more over the period. All the other three sectors showed an improvement in their PTE scores over the period. Over this period, the Aerospace sector also had the lowest PET scores, echoing the pattern of TE results. 
Table 0.7: Pure technical efficiency scores of five high-tech sectors in years 19982008

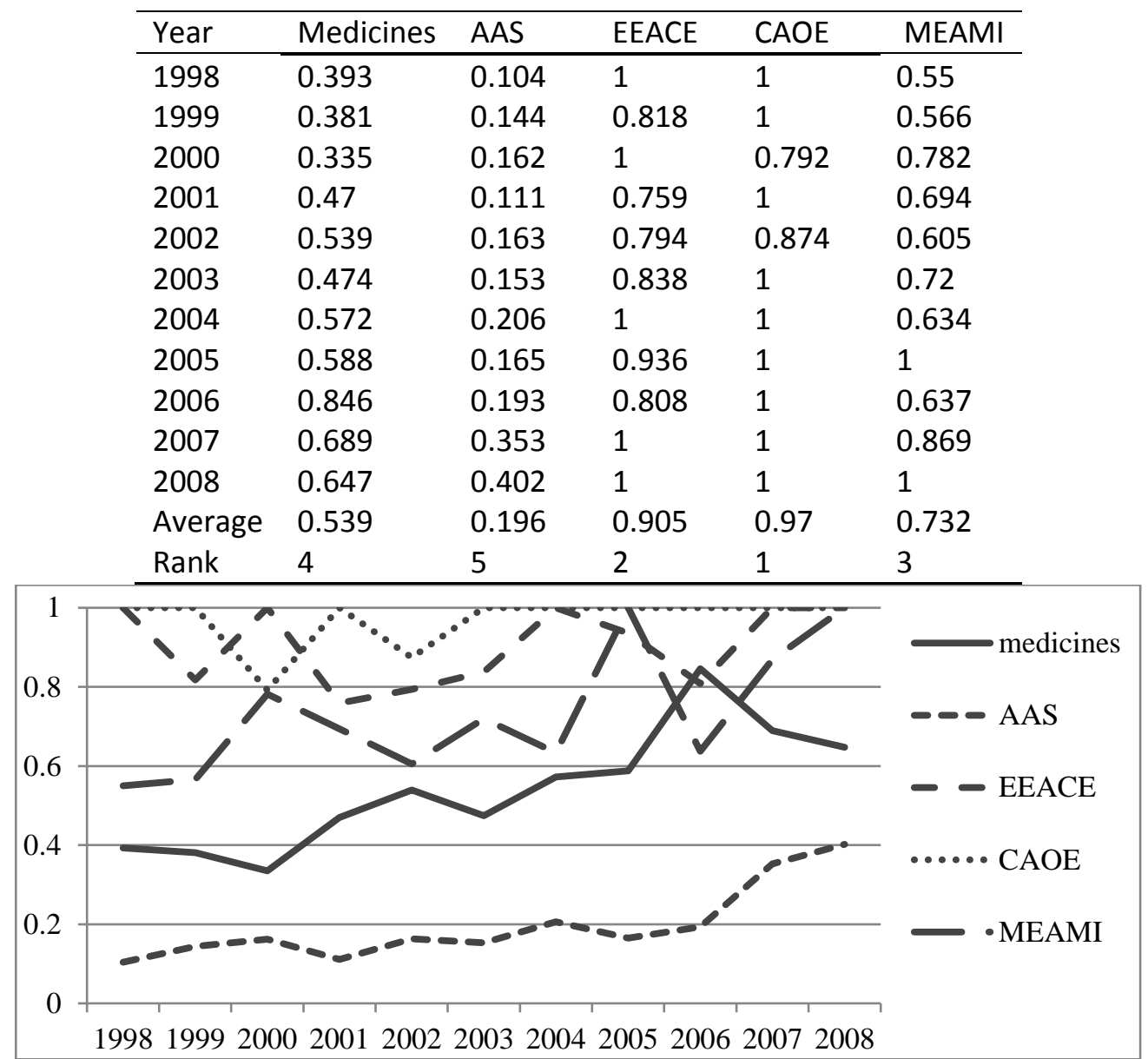

Figure 0.3: The annual variation of the R\&D investment PTE in five high-tech sectors from 1998 to 2008

\subsubsection{Scale Efficiency (SE)}

Scale efficiency (SE) scores, which reflect various classes of the returns to scale of $R \& D$ investment, didnot show any consistent pattern of change across the sectors during this period. SE was highest in the Medicine sector, followed by Instrument and Computer sectors (see Table 2.8 and Figure 2.4).

Table 0.8: Scale efficiency scores and returns to scale of five high-tech sectors in years 1998-2008

\begin{tabular}{llllllllllll}
\hline & \multicolumn{2}{c}{ Medicines } & AAS & & \multicolumn{2}{c}{ EEACE } & \multicolumn{2}{c}{ CAOE } & \multicolumn{3}{c}{ MEAMI } \\
\hline Year & SE & RTS & SE & RTS & SE & RTS & SE & RTS & SE & RTS \\
\hline 1998 & 0.97 & drs & 0.984 & irs & 0.598 & drs & 1 & - & 0.835 & Irs \\
1999 & 0.978 & irs & 0.981 & irs & 0.642 & drs & 1 & - & 0.896 & Irs
\end{tabular}




\begin{tabular}{lllllllllll}
2000 & 0.995 & drs & 0.966 & irs & 0.634 & drs & 0.909 & drs & 0.903 & Irs \\
2001 & 0.995 & irs & 0.796 & drs & 0.542 & drs & 0.833 & drs & 0.928 & Irs \\
2002 & 0.998 & irs & 0.85 & drs & 0.579 & drs & 0.875 & drs & 0.944 & Irs \\
2003 & 0.999 & drs & 0.801 & drs & 0.513 & drs & 1 & - & 0.963 & Irs \\
2004 & 0.932 & drs & 0.966 & drs & 0.506 & drs & 1 & - & 0.981 & Irs \\
2005 & 0.935 & drs & 0.583 & drs & 0.708 & drs & 1 & - & 0.993 & Irs \\
2006 & 0.911 & drs & 0.892 & drs & 0.921 & drs & 0.956 & drs & 0.993 & Drs \\
2007 & 1 & - & 0.958 & drs & 1 & - & 0.951 & drs & 0.988 & Drs \\
2008 & 0.978 & drs & 0.848 & drs & 1 & - & 0.887 & drs & 1 & - \\
Average & 0.972 & & 0.875 & & 0.695 & & 0.946 & & 0.948 & \\
Rank & 1 & & 4 & & 5 & & 3 & & 2 & \\
\hline
\end{tabular}

RTS is returns to scale. irs and drs for increasingand decreasing returns to scale, respectively.

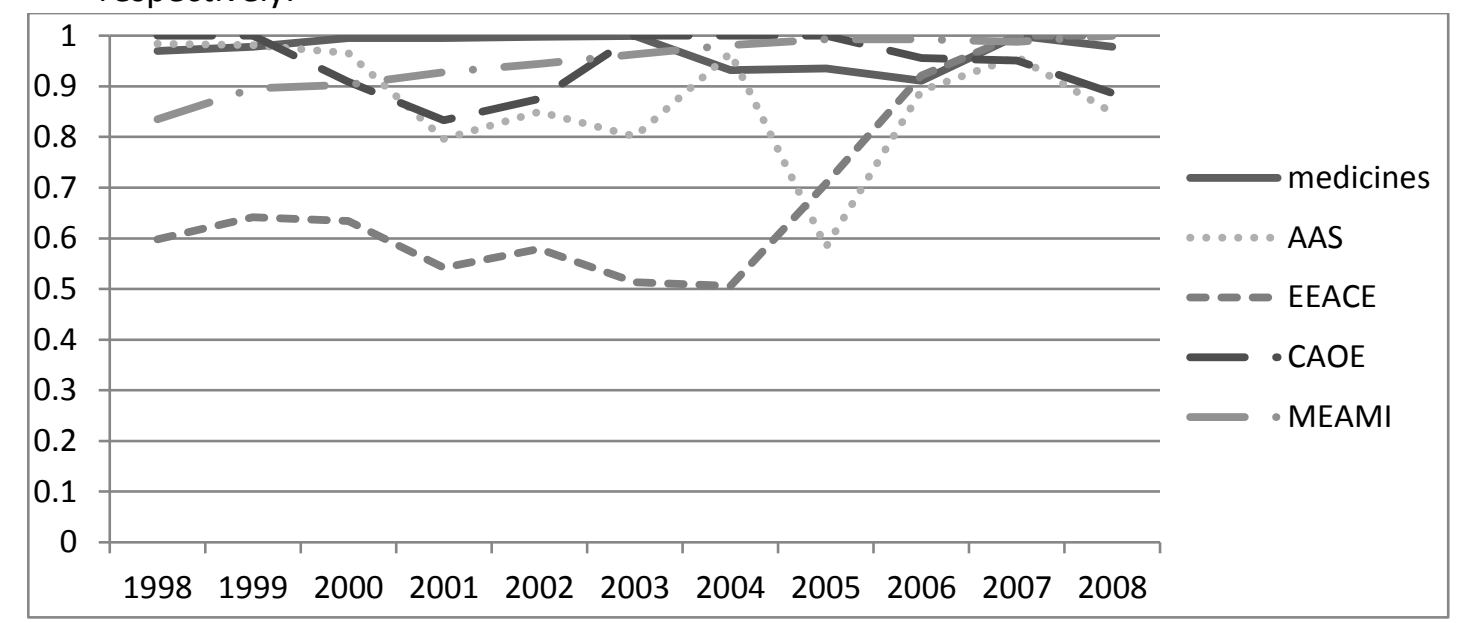

Figure 0.4: The annual variation of the scale efficiency scores in five high-tech sectors from 1998 to 2008

The average SE scores of the Electronics sector was the lowest of all the high-tech sectors althoughit has begun to increase since 2005. At the same time, the SE score of the Computer sector started to decline. Based on the observation of the SE score progress, the initial conclusionis that there appears no marked difference in returns to scale across the sector during this period. Further analysis of the SE data indicated that returns to scale (RS) metrics could provide useful indices for the management of R\&D investment efficiency. There are three possible classes of returns to scale: decreasing (DRS), increasing (IRS) and constant (CRS). CRS is indicated by an SE score of 1 ; DRS, signified by a decrease in the relative output for a given incremental input, and an associated decline in the consequent revenue/profit. The policy implications for such a sector appear to be that active monitoring and management of RS metrics may provide useful indices for controland allocation of R\&D investment. IRS, signified by an increase in the relative output for a given incremental input, suggests that for such a sector the incumbent 
$R \& D$ investment is insufficient to fully utilize the potential production capacity, therefore making the sector suffer from scale inefficiency. China's high-tech sectors suffered from DRS for most of the test period, with the exception of the Instrument sector. The Electronics and Instrument sectors both saw CRS, signifying the best scale efficiency performance in 2008; Electronics, suffered from DRS before 2007, whereasthe Instrument sector suffered from IRS before 2006.

In summary, it appears that most of the high-tech sectors in China have been suffering from decreasing returns to scale over the decade 1998-2008. This DRS trend may be a consequence of uncontrolled expansion of enterprises in these sectors, and/or increasing intensity of market competition. Another possible explanation is the monopolistic position of the high-tech sector in China, effectively reducing/removing competition.

\subsubsection{Individual Output/Input Ratio Analysis}

As shown in Table 2.9 and Table 2.10 , ratio analysis was employed to examine the differences on individual output/input items among the five sectors. Table 2.6 presents the ratios of number of patents over the three inputs respectively: $R \& D$ expenditure,R\&D personneland the accumulated patents stock. Here, sectors 1 to 5 represent the Medicines sector, Aerospace sector, Electronics sector, Computer sector, Instrument sector, respectively.

Table 0.9: Individual output/input ratio analysis in terms of number of patents in years 1998-2008

\begin{tabular}{|c|c|c|c|c|c|c|c|c|c|c|c|c|c|c|}
\hline \multirow{2}{*}{$\begin{array}{c}\text { ratio } \\
\text { measures }\end{array}$} & \multirow[t]{2}{*}{ sector } & \multicolumn{11}{|c|}{ year } & \multirow[t]{2}{*}{ average } & \multirow[t]{2}{*}{ rank } \\
\hline & & 998 & 1999 & 2000 & 2001 & 2002 & 2003 & 2004 & 2005 & 2006 & 2007 & 2008 & & \\
\hline patent & secto & 027 & 0.025 & 0.025 & 050 & .056 & 0.082 & .086 & .093 & 0.155 & 0.171 & 0.156 & & 3 \\
\hline number/f & sector 2 & 003 & 0.003 & 0.002 & .004 & 0.003 & 0.006 & 0.009 & .004 & 0.012 & .021 & 0.027 & 009 & 5 \\
\hline ull-time & sector 3 & & & & & & & & & & & & & 2 \\
\hline equi & sector 4 & ( & 0.019 & 0.0 & 5 & 0.091 & 0.242 & 0.186 & 202 & 0.150 & 0.237 & 0.187 & & 1 \\
\hline ce o & ector 5 & & .015 & 028 & 033 & .038 & 0.0 & .066 & & & & & & $\Lambda$ \\
\hline patent & sector & & & & & 008 & & & & & & & & \\
\hline number/R & sector 2 & 001 & 0.001 & 0.001 & 0.001 & 0.001 & 0.001 & 0.002 & 0.001 & 0.001 & 0.002 & 0.003 & .001 & 5 \\
\hline & sector 3 & 00 & 0.004 & 0.004 & 3 & 0.004 & 0.00 & 0.0 & .006 & 0.008 & 0.009 & 0.0 & & \\
\hline expendit & sector 4 & 006 & 0.004 & 0.002 & .006 & 0.007 & 0.008 & 0.011 & .005 & 0.007 & 0.008 & 0.008 & 009 & 3 \\
\hline & secto & & & & & & & & & & & & & 1 \\
\hline & sector 1 & & 2.434 & 2.1 & 2.442 & 3.168 & 2.41 & 4.237 & 3.5 & 5.900 & 2.642 & 2.695 & 96 & 4 \\
\hline & sector 2 & 0.908 & 1.946 & 2.447 & 0.434 & 1.737 & 1.266 & 2.686 & 1.230 & 2.326 & 6.986 & 4.219 & 381 & 5 \\
\hline number/p & sector 3 & 893 & 4.958 & 7.989 & & 5.150 & 5.019 & 5.9 & 6.541 & 5.249 & 6.811 & 5.783 & 5.538 & 2 \\
\hline & sector 4 & & & & & 8.087 & 7.275 & & & 6.875 & 4.530 & 6.905 & & 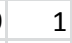 \\
\hline stocks & sector 5 & 2.128 & 3.293 & 3.484 & 3.213 & 1.913 & 2.976 & 2.792 & 6.333 & 2.343 & 3.735 & 4.457 & 3.333 & 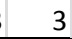 \\
\hline
\end{tabular}


Table 2.10 shows that: (1) The Computer sector performed at the best level on R\&D personnel ratio and patent stocks ratio. (2) The Instrument sector ranked first in R\&D expenditure ratio but did not perform well in the other ratios. (3) The Electronics sector ranked second in all output/input ratios. (4) The Aerospace sector operated least efficient among the five sectors. (5) The Medicines sector performed only better than the Aerospace sector. Noticeably, it ranked third in the $R \& D$ personnel ratio due to its consecutive increase in full-time equivalence productivity on patents between 2001 and 2007.

Table 2.10 represents the ratios of new product annual sales to three outputs in each industry: R\&D expenditure, $R \& D$ personnel and the accumulated patents stock. This analysis shows that the Computer sector and Electronics sector ranked first and second across every ratio. The Medicines sector and Instrument sector operated less efficiently, and again the Aerospace sector exhibited the lowest performance. This analysis supports the initial conclusion from the earlier analyses that the Computer sector is the most efficient sector within China's high-tech industry, followed with the Electronics sector and Instrument sector; the Aerospace sector has the worst performance on R\&D investment efficiency.

Table 0.10: Individual output/input ratio analysis in terms of new product annual sales in years 1998-2008

\begin{tabular}{|c|c|c|c|c|c|c|c|c|c|c|c|c|c|c|}
\hline \multirow{2}{*}{$\begin{array}{c}\text { ratio } \\
\text { measures }\end{array}$} & \multirow[t]{2}{*}{ sector } & \multicolumn{11}{|l|}{ year } & \multirow[t]{2}{*}{ average } & \multirow[t]{2}{*}{ rank } \\
\hline & & 1998 & 1999 & 2000 & 01 & 2002 & 2003 & 2004 & 2005 & 2006 & 2007 & 2008 & & \\
\hline new & $\mathrm{s}$ & 10.87 & 113.78 & 152.62 & 1.02 & 200.68 & 256.8 & 246.81 & 37.43 & .1 & 44.1 & 393.4 & & \\
\hline proc & sector 2 & & 4.708 & 0.222 & & 31 & 1.58 & 14 & & & 137 & 28.6 & & \\
\hline sales/full- & sector 3 & 30.81 & 361.06 & 579 & 639.8 & 729.48 & 819.8 & 90.52 & 14.71 & 05.8 & 862.5 & 577.2 & & 2 \\
\hline & sector & & & & & & & & & & & & & \\
\hline equivalen & sector 5 & .469 & 62.735 & 83 & & 83.929 & 146.8 & & & & 379.2 & 43.4 & & 4 \\
\hline & sector & & & 14 & & & 22. & & & & & & & \\
\hline & sector 2 & & 6.1262 & 0.224 & 13.765 & 16.617 & 15.79 & & & 95 & 13.48 & בy & & 5 \\
\hline & sector 3 & & & 08 & & & 43.61 & & & & & & & \\
\hline D & sector 4 & & 205.55 & .859 & 141.49 & 99.069 & 83.7 & & & 0.4 & 63.81 & 5.73 & & \\
\hline expendit & & & & & & & 27.19 & & & & & & & 3 \\
\hline & $\mathrm{sec}$ & & & 2873 & 926. & 112 & 752 & & & & 6858 & & & \\
\hline & sector 2 & 2.4 & 10292 & 21684 & 5418.5 & 26361 & 15879 & & 677 & 359 & 5081 & 20003 & 6.8 & 3 \\
\hline & secto & & 978 & 1757 & 80994 & 71024 & 5097 & 21 & & & 212 & & & \\
\hline & sector 4 & & & 527 & & & 74797 & & & 97839 & 363 & $25 / 8$ & & \\
\hline ent stocks & sector 5 & 8444.5 & 13891 & 10528 & 9012.5 & 4255.3 & 6941 & 6347.1 & 12686 & 5516 & 8409 & 6468 & 8408.89 & \\
\hline
\end{tabular}

\subsubsection{Summary of Analysis: Sector-level Indices}

Based on the analysis of the TE, PTE, SE and output/input ratio, the Computer sector achieved the best R\&D investment efficiency among China's five biggest high-tech sectors. However, apparently suffering from decreasing returns to scale, its 
efficiency has been declining since 2006. On present trends, the Electronics sector and Instrument sector might be predicted to overtake the Computer sector, as the best R\&D investment efficient high-tech sector in China, based on their performance in the test of DEA and output/input ratio. The other two sectors - medicines sector and Aerospace sector have been suffering from low R\&D investment efficiency, which may come from the effects of monopoly, and may call into question that investment strategy.

\subsubsection{Detailed Sub-sector Analysis}

Following on from the sector-level ratio analysis, the $R \& D$ investment efficiency within specific sub-sectors was moved on to explore. Of the 21 high-tech subsectors covered in the Bureau data, only 16 could be accepted into analysis: 5 had to be excluded because of incomplete data. More detailed analysis of the 16 defined sub-sectors revealed that their individual R\&D investment efficiencies changed dramatically in year 2001 and 2008.

The overall pattern which emerges from the sub-sector analysis is of gradual decline in TE and PTE, some rise in SE and a fairly dramatic rise in the number of subsectors undergoing DRS. Over the same sample period, average SE scores across the sub-sectors were increasing, and the number of sub-sectors which were suffering from DRS rose dramatically. In addition, fewer sub-sectors were performing with high R\&D investment efficiency (see Table 2.11). In Figure2.5(a) and 2.5(b), the distribution of PTE/TE ratios was plotted, and indicate their relationship to the average PTE and TE scores (solid lines).In Figure 2.6(a) and 2.6(b), the situation as a series of four-quadrant grids framing the potential zones of behaviour between key parameters was portrayed. The positive relationship between TE score and PTE score in Figure2.5a could be observed. And the relationship is much stronger in Figure2.5b, which suggests the PTE level is more important in improving the TE score.

In Figure 2.5a: (1) The lines perpendicular to the $x$-axis and the $y$-axis are, respectively, the average value of the TE score and PTE score for the 16 high-tech sectors, (2) The numbered points on the grid represent the individual sectors represented in table 2.11 .

In Figure 2.5b: (1) the lines which are perpendicular to the $x$-axis and the $y$-axis are, respectively, average value of TE and PTE scores of 16 sub-sectors, that is $x=0.599$, 
$y=0.747$. (2) The numbers represent the various sub-sectors in Table 2.11. Figure $2.5 \mathrm{~b}$ shows the equivalent data for 2008 on the same axes.

In both Figure 2.5a and 2.5b, the sectors in zone A exhibit both high PTE and TE scores. Sectors in zone B show high PTE scores, but low TE scores. Zone C sectors exhibit low score on both PTE and TE. There are few sectors in zone D, making high TE score with low PTE level an uncommon occurrence.

Table 0.11: Process efficiency scores of R\&D investment in 16 China's high-tech sub-sectors in 2001 and 2008

\begin{tabular}{|c|c|c|c|c|c|c|c|c|c|c|}
\hline \multirow[t]{2}{*}{ Ind. } & \multirow{2}{*}{$\begin{array}{l}\text { *Sub- } \\
\text { sector } \\
\text { NO. }\end{array}$} & \multirow[t]{2}{*}{ Abbr. } & \multicolumn{2}{|c|}{$\mathrm{TE}$} & \multicolumn{2}{|c|}{ PTE } & \multicolumn{2}{|c|}{ SE } & \multicolumn{2}{|c|}{ RTS } \\
\hline & & & 2001 & 2008 & 2001 & 2008 & 2001 & 2008 & 2001 & 2008 \\
\hline \multirow{3}{*}{ medicines } & 1 & $\mathrm{CM}$ & 0.533 & 0.314 & 0.97 & 0.54 & 0.55 & 0.581 & drs & Drs \\
\hline & 2 & FTCHM & 1 & 0.551 & 1 & 0.959 & 1 & 0.575 & - & Drs \\
\hline & 3 & $\mathrm{BABCP}$ & 0.429 & 0.562 & 1 & 0.575 & 0.429 & 0.977 & irs & Irs \\
\hline AAS & 4 & ROA & 0.104 & 0.234 & 0.237 & 0.413 & 0.44 & 0.566 & drs & Drs \\
\hline \multirow{8}{*}{ EEACE } & 6 & CTRE & 0.363 & 0.535 & 0.375 & 0.787 & 0.967 & 0.68 & irs & Drs \\
\hline & 8 & CTEE & 1 & 0.252 & 1 & 0.255 & 1 & 0.987 & - & Irs \\
\hline & 11 & EVA & 0.672 & 0.389 & 0.778 & 0.394 & 0.863 & 0.986 & irs & Irs \\
\hline & 12 & SDA & 0.245 & 0.335 & 1 & 0.469 & 0.245 & 0.715 & irs & Irs \\
\hline & 13 & IC & 0.399 & 0.786 & 1 & 1 & 0.399 & 0.786 & irs & Drs \\
\hline & 14 & ELC & 0.418 & 0.367 & 0.544 & 0.585 & 0.77 & 0.628 & drs & Drs \\
\hline & 15 & DTSARR & 1 & 0.816 & 1 & 1 & 1 & 0.816 & - & Drs \\
\hline & 16 & OEE & 0.576 & 1 & 1 & 1 & 0.576 & 1 & irs & - \\
\hline \multirow{2}{*}{ CAOE } & 17 & ENC & 1 & 1 & 1 & 1 & 1 & 1 & - & - \\
\hline & 18 & CPE & 0.869 & 0.88 & 0.926 & 1 & 0.939 & 0.88 & drs & Drs \\
\hline \multirow{2}{*}{ MEAMI } & 20 & MEAA & 1 & 1 & 1 & 1 & 1 & 1 & - & - \\
\hline & 21 & $\mathrm{MI}$ & 0.689 & 0.564 & 0.85 & 0.977 & 0.811 & 0.577 & drs & Drs \\
\hline & mean & & 0.644 & 0.599 & 0.855 & 0.747 & 0.749 & 0.797 & & \\
\hline
\end{tabular}

Figure 2.6 shows the shift in the PTE and TE scores of the 16 sub-sectors between 2001 and 2008. This analysis reveals no sub-sector staying in Zones B or C in 2008; more sub-sectors appear in Zone $A$ and $B$. These changes indicate that the overall Scale efficiency level across the 16 sub-sectors improved, which may be the 
consequence of the consistent increase of $R \& D$ investment inputs in China. However, a decline of the PTE level across these sub-sectors accompanied the SE improvement, which again highlights the importance of PTE improvement as a key management index for the increasing of overall R\&D investment efficiency level within China's high-tech sub-sectors.

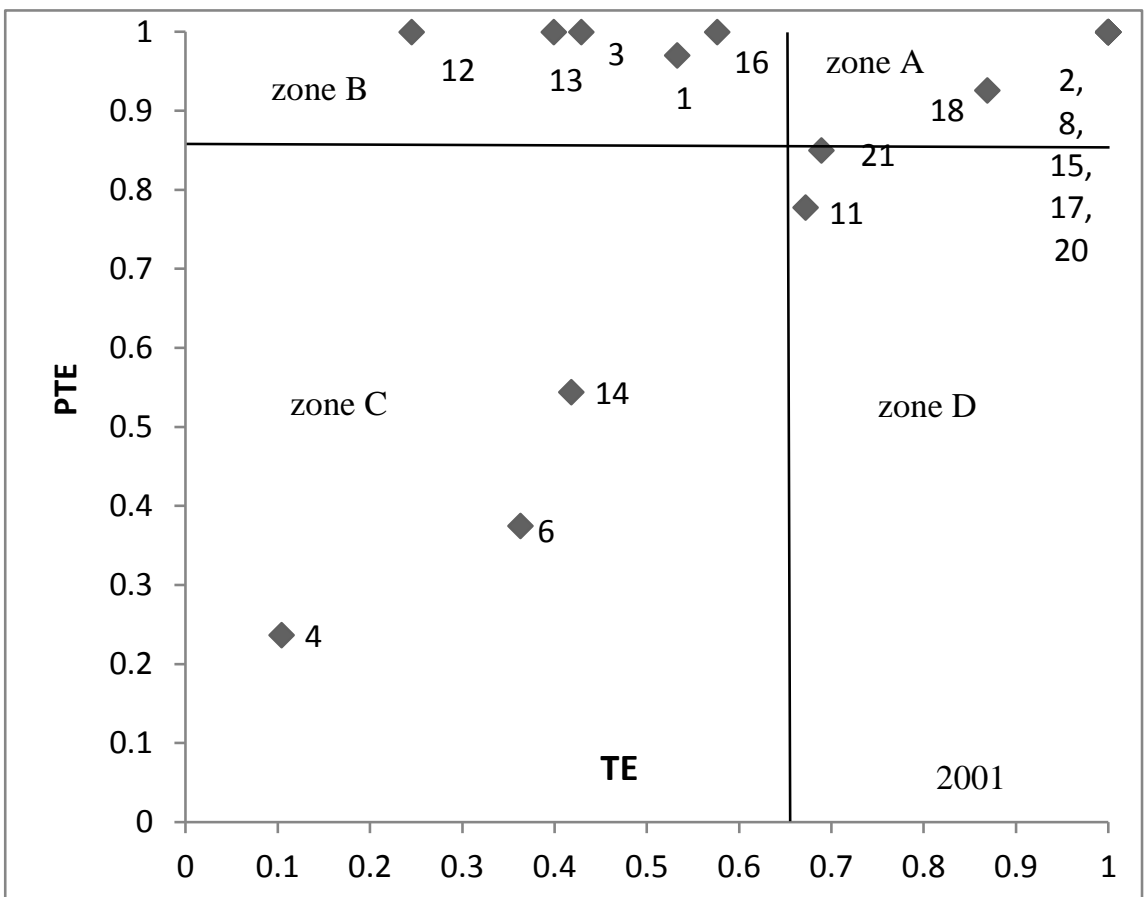

Figure 2.5a: the comparison of PTE and TE scores of 16 sub-sectors in 2001 


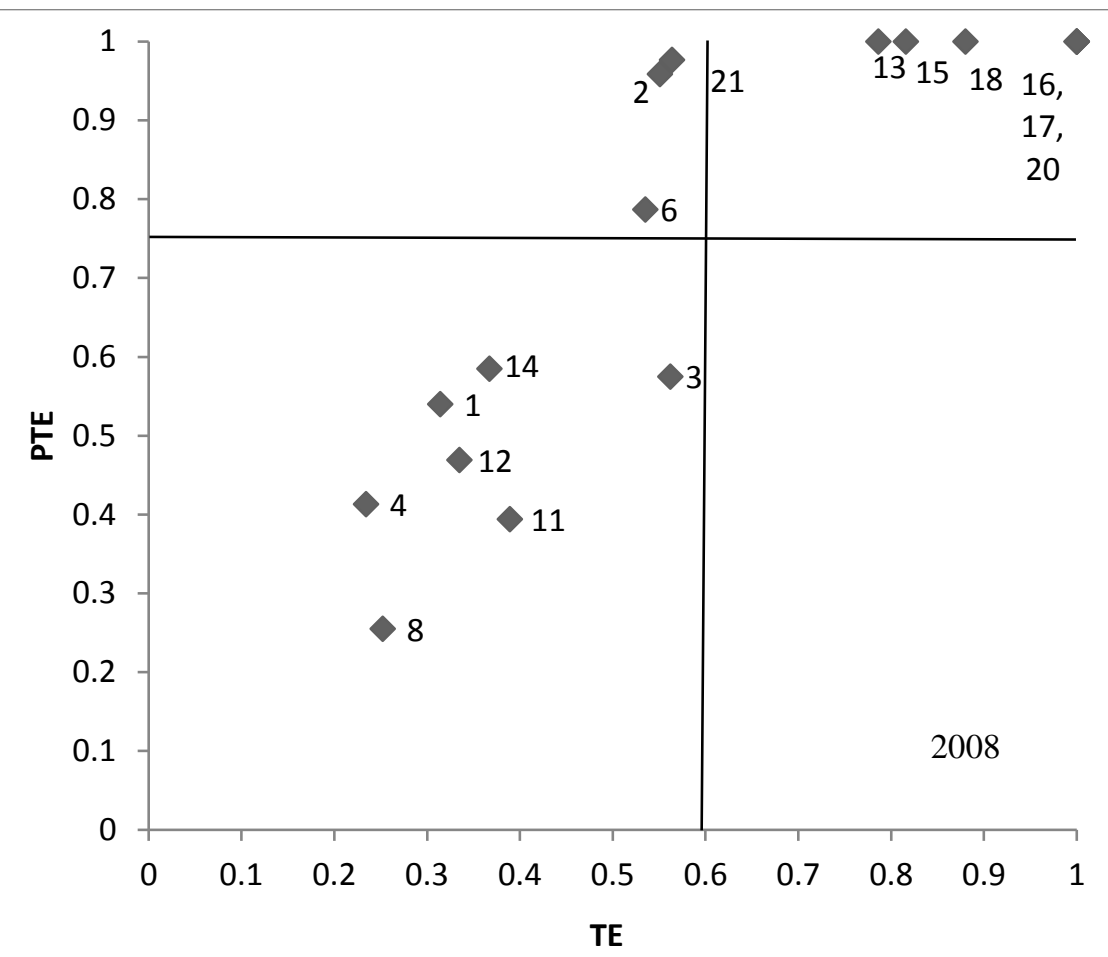

Figure 2.5b: The comparison of PTE and TE scores of 16 sub-sectors in 2008

Figure 0.5: The comparison of PTE and TE scores of 16 sub-sectors in 2001 and 2008 


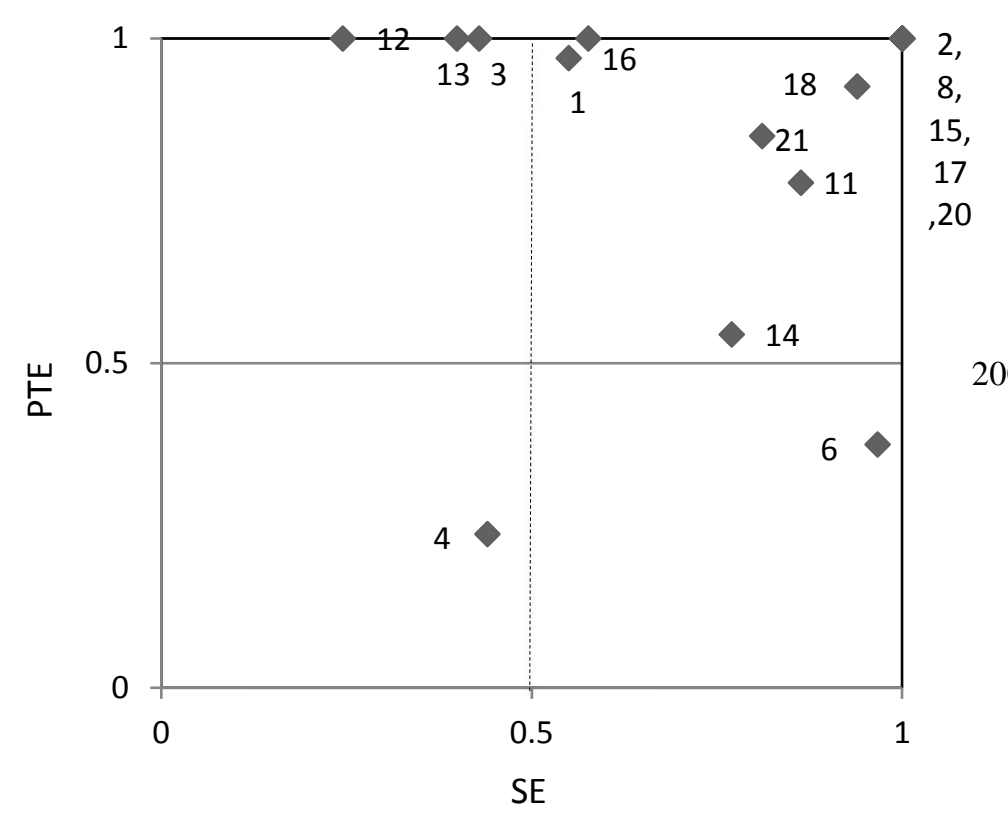

2001

Figure 2.6a: The comparison of PTE and SE scores of 16 sub-sectors in 2001

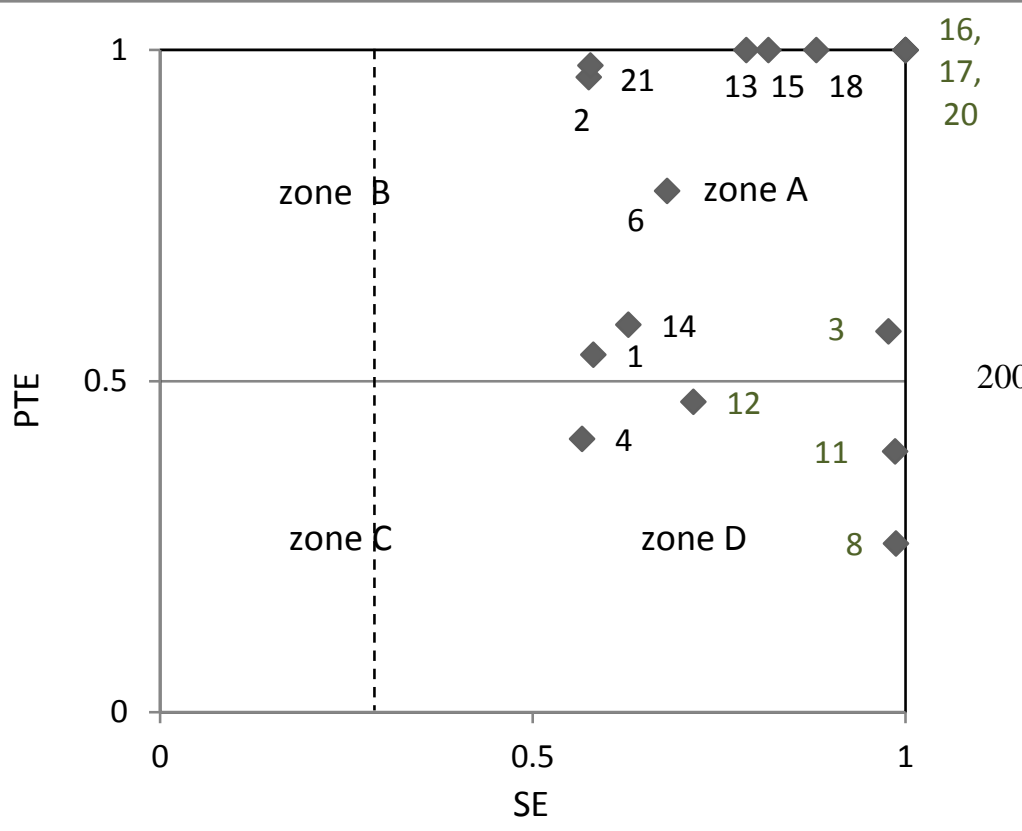

Figure 2.6b: The comparison of PTE and SE scores of 16 sub-sectors in 2008

Figure 0.6: The comparison of PTE and SE scores of 16 sub-sectors in 2001 and 2008

There are three sub-sectors in the Medicine sector: Chemical Medicine, Herbal Medicine, and Biological Products. Chemical Medicine sub-sector (CM) and Herbal Medicine sub-sector (FTCHM), which were separately suffering from the decreasing of PTE and CE experienced the decreasing R\&D efficiency. Biological Products sub- 
sector (BABCP) which was benefit from the great improvement of its $C E$, improved a little in its TE. Airplanes sub-sector (ORA) -- part of the Aerospace sector, improved its R\&D investment efficiency through the development of both PTE and CE. In the Electronics sector, four sub-sectors (CTRE, SDA, IC, and OEE) which most benefited from the improvement of PTE, increased their TE score during year 2001 to 2008. The other four sub-sectors in Electronics sector experienced the decreasing of TE based on different reasons. Entire Computer sub-sector (ENC) from the Computer sector and Medical Equipment sub-sector (MEAA) from the Instrument sector were the most efficient sub-sectors about R\&D investment both in year 2001 and 2008 .

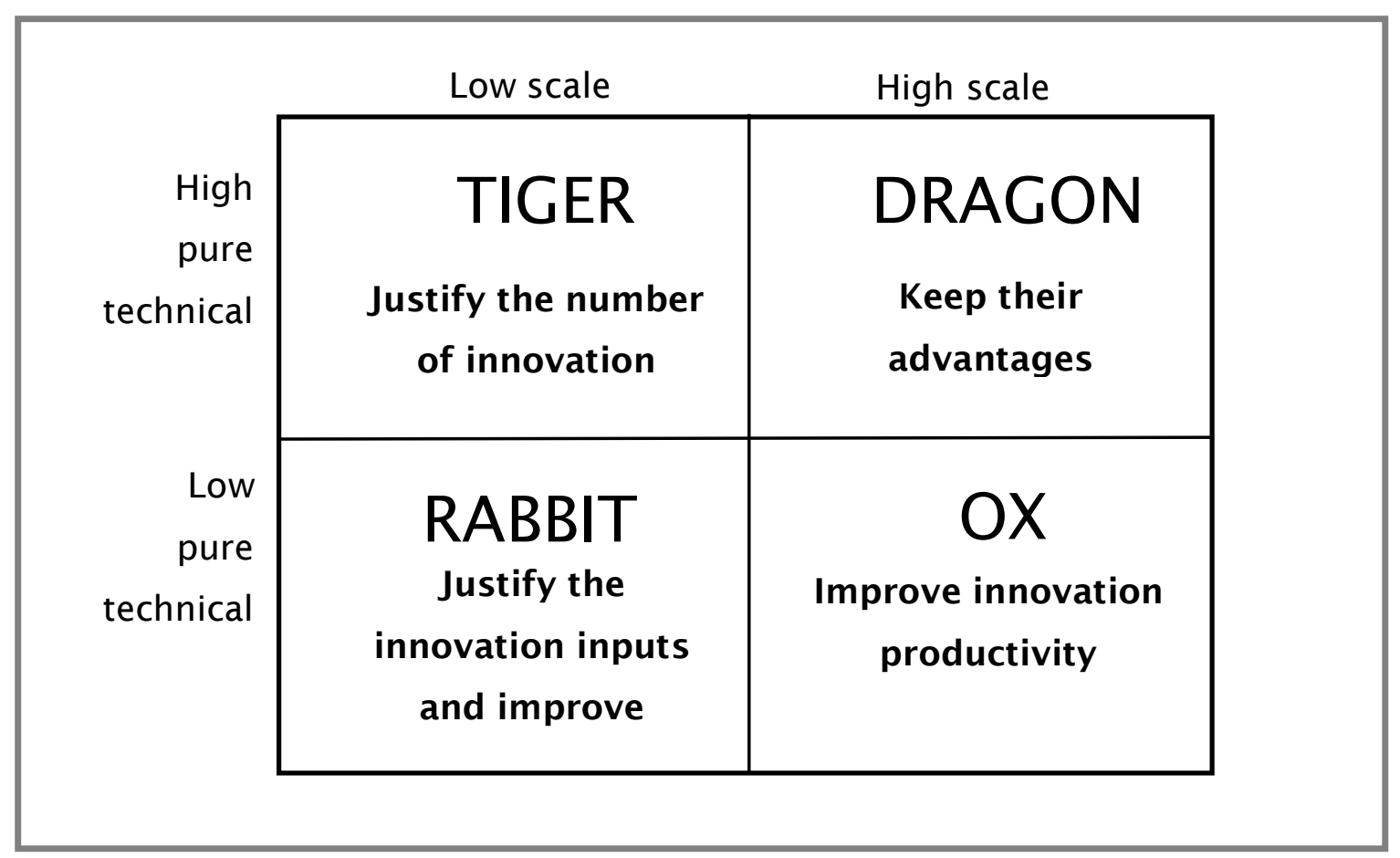

Figure 0.7: Proposed strategy grid for companies/sectors with varying levels of technical efficiency and scale

Based on the above study, a model (see figure 2.7) is designed to help industries evaluate their positions on these key indices of innovation and identify the most appropriate actionable strategies/steps to improve their R\&D investment efficiency.

Dragon Zone sectors are in a strong position: for sectors in this zone, the amount of $R \& D$ investment input is sufficient, leading to the best returns to the scale; the capacity of resource allocation and innovation productivity is near optimal, leading to highest R\&D investment output. This is the desired goal for most if not all sectors each. 
Tiger Zone: for sectors in this zone, the capacity of resource allocation and innovation productivity is also approaching the optimum, favouring high $R \& D$ investment output, but the level of R\&D investment inputs is suboptimal leading to decreasing or increasing returns to the scale scenarios (DRS or IRS). To move to the Dragon zone, companies in the Tiger zone, firstly need to identify the polarity of their scale inefficiency - decreasing returns to the scale (DRS) which implies R\&D investment inputs have been used inefficiently, or increasing returns to the scale (IRS) which suggests $R \& D$ investment inputs is insufficient to exploit fully the company/sector's capacity. Secondly, based on the earlier analysis, companies/sectors could adopt a different course of action - increasing R\&D investment inputs if suffering from IRS, or decreasing R\&D investment inputs if the industry is showing signs of DRS effects.

Ox Zone: for companies/sectors in this zone, the amount of R\&D investment input is sufficient but not excessive, leading to the best returns to scale. But resource allocation and innovation productivity is relatively weak, producing the observed $R \& D$ investment inefficiency. Sectors or companies in this zone need to apply $R \& D$ investment more efficiently, and improvinginnovation productivity is the main approach.

Rabbit Zone: companies or sectors in this zone are likely to have issues both on the scale of R\&D investment and innovation productivity. The immediate needs are therefore to judge which scale problem is in effect - IRS or DRS,then attempt to change the quality and level of the R\&D investment inputs, and also concentrate on improving the pure technical efficiency.

For policy makers, the findings and the proposed model suggest that companies or sectors:

(1) Keep the advantage of 'Dragon' industries, which is the most efficient engine for economic growth;

(2) Give policy support to help control the R\&D investment inputs in 'Tiger' industries, which are the potential high efficient engine for economic growth;

(3) Help to control the R\&D investment inputs in 'Rabbit' industry, that is the fast way to improve their R\&D investment efficiency; 
(4) Help both 'Rabbit' and 'Ox' industries to improve their resource allocation ability and innovation productivity, which might take a longer time to catch.

\section{$1.4 \quad$ Concluding Remarks}

This study applied the CCR (which is designed under the assumption that production exhibits constant returns to scale) and BCC (which assumes that there are variable returns to scale) DEA models to evaluate the relative efficiency of $R \& D$ investments in China's high-tech industries. The principal econometric inputs employed were $R \& D$ expenditure, $R \& D$ personnel full-time equivalent (FTE), and the accumulated patents stock. Three main outputs were selected: the number of applied patents number, the value-added from new products and the sale revenue for new products. The subsequent analysis was conducted at three different levels: across the entire high-tech industry, across the five major high-tech sectors, and then across the 16 high-tech sub-sectors, as defined in the source of Chinese government data.

The primary results from this study are that: the R\&D investment efficiency in China's high-tech industry was nearly unchanged over test period; most of the sectors showed significant fluctuation on R\&D investment efficiency over the period; average SE increasedamong sub-sectors, and these findings were discussed in more detail in the ensuing sections.

\subsubsection{Lack of Immediate Impact of R\&D Investment}

The first and most striking result of the analysis at the overall high-tech industry level indicates that the R\&D investment efficiency in China's high-tech industry was nearly unchanged over the period 1998 to 2009. It is perhaps little surprising that the overall R\&D investment performance of high-tech industry didn't show any increase, even though the R\&D expenditure steadily increased during the examination period. Further analysis revealed that the increased R\&D expenditure was associated with a dramatic increase (see Figure 2.1) in the number of patent stock, yet there was a limited increase of the economic return from new products over the high-tech industry. This finding suggests that the increase of the R\&D inputs has brought the obvious improvement of the technology production efficiency, but that hasn't yet led to an equivalent improvement in the efficiency of 
the technology commercialization. This may be one reason why the R\&D investment of the whole high-tech industry did not perform better during the study period.

\subsubsection{Variable and Fluctuating Performance across Sectors}

Most of the sectors showed significant fluctuation on $R \& D$ investment efficiency over the period. All of them except the Instrument sector were suffered from DRS in most test years. The Computer sector performed the highest on R\&D investment efficiency but declined since 2006. Both Electronics and Instrument sectors showed the potential of being the most $R \& D$ investment efficient sectors in China. The R\&D investment efficiency of the Aerospace sector was lowest among the five sectors in China.

There are three indices observed through DEA analysis: TE score, PTE score and SE score.For TE score, the Computer sector (CAOE) was highest for many years. The Electronics sector (EEACE) and the Instrument sector (MEAMI) performed well following the Computer sector. Aerospace (AAS) performed lowest of the five hightech sectors. However the TE score of the Computer sector started to decline in 2006. Compared with the decline of computer sector, Electronics and Instrument sectors experienced an improvement of TE scores over period.

The PTE scores showed a similar pattern to the TE analysis. The Computer sector achieved the highest and most consistent PTE scores during 1998 to 2008. Electronics sector were second highest but unstable over the period. All the other three sectors showed an improvement in their PTE scores. And the Aerospace sector still owned the lowest PET scores, similar to the TE results.

Scale efficiency (SE) scores didn't show any consistent pattern of change across the sectors during this period. SE was highest in the Medicine sector, followed by Instrument and Computer sectors (see Table 2.8 and Fig. 2.4). The average SE scores of the Electronics sector was the lowest of all the high-tech sectors although it has begun to increase since 2005. And at the same time, the SE score of the Computer sector started to decline in 2006. Further analysis of the SE data indicated that China's high-tech sectors suffered from DRS for most of the test period, with the exception of the Instrument sector. 


\subsubsection{Average SE Increased Among Sub-sectors}

Sixteen high-tech second-class sub-sectors were chosen and tested. The result comparison between 2001 and 2008 showed that, their R\&D investment efficiencies changed dramatically. Their average TE score decreased with the decreasing average PTE score. The average SE scores across the sub-sectors however, were increasing. At the same time, sub-sectors were suffering from the decreasing returns to scale.

\subsubsection{Summary Conclusion}

In summary, China's high-tech industries would still appear to need time to improve their R\&D investment efficiency. In the past, many Chinese scholars and government officials have argued that China's high-tech industries should first increase their R\&D investment to the level or close to the level of that in developed countries, in order to reach the same scientific and technological level of western countries (Zhong et al., 2011). However, the DEA analysis of this study illustrates that despite a continuous increase of the R\&D investment input, the efficiency of the R\&D investment has not yet showed a clear and consistent improvement. On the contrary, more sectors and sub-sectors suffered from the decreasing returns to scale, which may be due to the low absorptive capacity for the potential outputs of the increasing R\&D inputs.

On the other hand, some scholars and government officials have emphasized that China needs to enhance the capacity for independent innovation. However, comparing the huge increase of the applied patents number with the unchanged $R \& D$ investment efficiency, the conclusion is that the problem of China's high-tech industry may not be its lack of independent innovation, but the inefficiency of its technology commercialization processes. Of course, this low commercialization performance may stem from low quality of independent innovation. This hypothesis could be examined in further research, by the study of innovation productivity process in China's high-tech industry. 


\section{References}

Avkiran, N. K., Rowlands, T., 2008. How to better identify the true managerial performance: State of the art using DEA. Omega 36, 317-324.

Banker, R. D., Charnes, A., Cooper, W. W., 1984. Some models for the Estimation of Technical and Scale Inefficiencies in Data Envelopment Analysis. Management Science 30, 1078-1092.

Cainelli, G., Evangelista, R., Savona, M., 2006. Innovation and economic performance in services: a firm-level analysis. Cambridge Journal of Economics 30, $435-458$

Charnes, A., Cooper, W. W., Rhodes, E., 1978. Measuring the Efficiency of Decision Making Units. European Journal of Operations Research 2, 429-444.

Chen, C.J., Wu, H.L., Lin, B.W., 2006. Evaluating the development of high-tech industries: Taiwan's science park. Technological Forecasting \&Social Change 73, 452-465.

Cooper, W. W., Seiford, L.M., Zhu, J., 2004. Handbook on Data Envelopment Analysis.Springer. Boston.

Furman, J.L., Porter, M.E., Stern, S., 2002. The determinants of national innovative capacity. Research Policy 31, 899-933.

Grossman, G., Helpman, E., 1991. Innovation and growth in the global economy. MA: MIT Press. Cambridge.

Guan, J.C., Chen, K.H., 2010.Measuring the innovation production process: A crossregion empirical study of China's high-tech innovations.Technovation 30, 348-358.

Gulati, R., 2011 . Evaluation of technical, pure technical and scale efficiencies of Indian banks: An analysis from cross-sectional perspective. The 13th Annual Conference on Money and Finance in the Indian Economy.

Hollanders, H., Celikel-Esser, F., 2007.Measuring innovation efficiency. INNO Metrics 2007 report, Brussels: European Commission, DG Enterprise.

Hu, M.C., Mathews, J.A., 2008. China's national innovative capacity. Research Policy $37,1465-1479$. 
Kozmetsky, G., Yue, P., 1998. Comparative performance of global semiconductor companies. Omega 26, 153-175.

Iglesias, G., Castellanos, P., Seijas, A., 2010. Measurement of productive efficiency with frontier methods: A case study for wind farms. Energy Economics 32, 1199 1208.

Ministry of Science and Technology of the People's Republic of China, 2009.China Science and Technology Indicators 2008.Scientific and Technical Documents Publishing House. Beijing.

Ministry of Science and Technology of the People's Republic of China, 2007.China Science and Technology Indicators 2006.Scientific and Technical Documents Publishing House. Beijing.

Ministry of Science and Technology of the People's Republic of China, 2001.China Science and Technology Indicators 2000.Scientific and Technical Documents Publishing House. Beijing.

Reinhard, S., Lovell, C. A. K., Thijssen, G. J., 2000. Environmental efficiency with multiple environmentally detrimental variables: estimated with SFA and DEA. European Journal of Operational Research 121, 287-303.

Romer, P., 1990.Endogenous technological change. Journal of Political Economy 98, 71-102.

Rosegger, G., 1996. The Economics of Production and Innovation.ButterworthHeinemann. Oxford.

Rousseau, S., Rousseau, R., 1997.Data envelopment analysis as a tool for constructing scientometrics indicators.Scientometrics 40, 45-56.

Rousseau, S., Rousseau, R., 1998. The scientific wealth of European nations: taking effectiveness into account. Scientometrics 42, 75-87.

Sharma, S., Thomas, V. J., Inter-country R\&D efficiency analysis: An application of data envelopment analysis. Scientometrics 76, 483-501.

The Royal society, 2011 . Knowledge, networks and nations: Global scientific collaboration in 21 st century. Elsevier. London. 
Wang, E. C., Huang, W., 2007. Relative efficiency of R\&D activities: A cross-country study accounting for environmental factors in the DEA approach. Research Policy 36, 260-273.

Xing, Y. Q., 2011 . China's High-tech exports: Myth and Reality. GRIPS Discussion Paper.

Yeh, Q., 1996. The application of data envelopment analysis in conjunction with financial ratios for bank performance evaluation. Journal of Operational Society 47 , 980-988.

Zabala-Iturriagagoitia, J.M., Voigt, P., Gutierrez-Gracia, A., Jimenez-Saez, F., 2007. Regional innovation systems: how to assess performance. Regional Studies 41, 661 672.

Zhong, W., Yuan, W., Li, S.X., Huang, Z.M., 2011. The performance evaluation of regional R\&D investments in China: An application of DEA based on the first official China economic census data. Omega 39, 447-455. 